Portland State University

PDXScholar

\title{
"Conservatism in a Revolutionary Era:" an Analysis of Challenges Posed by Developing an Exhibit of the Americanism Collection
}

Mariah C. Denman

Portland State University

Follow this and additional works at: https://pdxscholar.library.pdx.edu/honorstheses

Let us know how access to this document benefits you.

\section{Recommended Citation}

Denman, Mariah C., "'Conservatism in a Revolutionary Era:" an Analysis of Challenges Posed by Developing an Exhibit of the Americanism Collection" (2017). University Honors Theses. Paper 406. https://doi.org/10.15760/honors.402

This Thesis is brought to you for free and open access. It has been accepted for inclusion in University Honors Theses by an authorized administrator of PDXScholar. Please contact us if we can make this document more accessible: pdxscholar@pdx.edu. 


\title{
"Conservatism in a Revolutionary Era"
}

An analysis of challenges posed by developing an exhibit of the Americanism Collection

\author{
by \\ Mariah C. Denman \\ An undergraduate Honors thesis submitted in partial fulfillment of the requirements for the \\ degree of \\ Bachelor of Arts \\ in University Honors \\ And \\ Applied Linguistics \\ Thesis Advisor: \\ Cristine Paschild
}

2017

Portland State University

Introduction

${ }^{1}$ Young Americans for Freedom, Box 16, Charles White Americanism Collection, Portland State University Archives \& Special Collections, Portland. 
The goal of the "Conservatism in a Revolutionary Era" project was to develop an exhibit of selected documents from the Americanism Collection while exploring the challenges of exhibit-making with regard to the political nature of the records. Exhibit-making involves the study, curation, description, and display of materials for public consumption, and this paper will include reflections on my experiences in each phase of that process. Firstly, I will introduce the Collection and the Young Americans for Freedom organization which I centered in the exhibit. Secondly, I will address why I chose this project and how I arrived at the current juncture. Thirdly, I will lay out the intellectual framework of the project by introducing secondary source material (from both archival science and linguistics discourse communities) which inspired my thinking. Fourthly, I will give a brief description of the method by which I developed the exhibit. Finally, I will synthesize the project by applying my commentary to the secondary sources and delving deeper into my experiences through a reflective discussion.

\section{Meet the Collection}

The Charles M. White Americanism Collection is a collection of mailings, pamphlets, letters, magazines, newspapers, and newsletters related to a wide variety of far-right political and religious organizations from the mid-1950s to the early 1980s. This collection was established by Dr. Charles White, Professor Emeritus of History at Portland State University. In a 2009 interview for the PSU Archives \& Special Collections Faculty Oral History Project, Dr. White expressed his academic interest in both the far-left and far-right fringes of American political culture. ${ }^{2}$ Dr. White's Americanism Collection was intended to focus on the far-right, especially the increasingly Christian-oriented conservatism emerging the 1950s. The Collection includes materials from a broad spectrum of conservative organizations. Of those groups, I have chosen to focus on the Young Americans for Freedom.

The YAF is a conservative youth organization formed in 1960 by William F. Buckley, Jr. and several of his contemporaries. The group was founded on the idea of promoting conservative values in

\footnotetext{
${ }^{2}$ Charles M. White Interview. Performed by Charles M. White and Michelle Trappen. United States: Portland State University, 2009. DVD.
} 
young people during a time of heavy political mobilization by the left wing in the U.S and abroad. Today, YAF still operates on a number of college campuses under the umbrella of the For America Foundation. The new iteration of the YAF boasts many of the same goals as it did in 1960: to promote the appreciation and understanding of free enterprise, national defense, limited government, and "traditional" values to young people.

\section{Meet the Project}

The goal of this project was to develop a public exhibit of materials from the Americanism Collection and to write an analysis/reflection concerning the challenges posed by the process of engaging with controversial, politically-oriented documents and displaying/interpreting them for an audience. I began my work in the Collection in the fall of 2015 and spent two terms studying the twenty-eight boxes as best I could. In the fall of 2016, I decided that I wanted a) to design an exhibit and b) the exhibit to center around YAF. YAF is a student/campus conservative activist group, and Portland State is, in my view, an activist campus - all across the political spectrum. I felt that focusing on campus activism would resonate with many students and faculty. Further, I anticipated that focusing on one group and its ideologies, activities, and materials would allow me to perform a deeper analysis and therefore provide a more meaningful, interesting exhibit. By contrast, I could have attempted to design an exhibit of all the Collection's Vietnam-related materials. Such a project would have taken me far beyond the scope of an Honors undergraduate thesis, and the resulting exhibit would have been too broad, with much more room for misinterpretation.

As an Applied Linguistics major, part of what interested me in archives in the first place was the idea of an archive as a repository of discourse waiting to be analyzed. The research I conducted for this project allowed me to engage with archival science literature concerned with a variety of issues, such as narrative and description/representation; critical approaches to imperialism, colonialism, capitalism, gender, and race, socio-political conflict, etc., as they relate to archives. Moreover, critical discourse analysis is the practice of examining the above-mentioned issues with regard to how a text - a newspaper, a Presidential speech, a personal letter-demonstrates its 'identity' as part of a larger discourse (e.g how 
does a certain New York Times author identify themselves as politically conservative through word choice, rhetorical strategies, verb tense, etc.). In that vein, studying the Americanism Collection was a broad examination of how YAF enacted its politically conservative identity through its letters and publications, with the end product of that study being an exhibit rather than a formal linguistic analysis.

Exhibit-making appeared to be a natural bridge between my interests in archives and discourse. I saw it as a creative means of metacognition about how one experiences discourse from the past in a modern context, and how one maintains a sense of neutrality when confronted with material from an opposing worldview. Throughout the process, I felt that every decision I made was shaped by my political convictions, even when I was not explicitly making politically-charged narrative/descriptive decisions about the exhibit. As the literature demonstrates, and as my discussion will elaborate, grappling with objectivity is the greatest challenge of archival description/exhibit-making. While this project strayed from traditional linguistic methodology, it was informed by a notion that linguists generally agree on: language is imperfect and inherently context-driven, biased, and subjective.

\section{Meet the Sources}

Within the greater body of the field of archival science, certain scholars are building a movement of what I would call "critical archival science," where approaches to archives and their curation, retention, and display are increasingly concerned with the sociocultural/political power relationships behind them. Exposure to sources likes these solidified my attraction to the exhibit-making process and its greater implications because I saw an opportunity to blend critical approaches to discourse with the act of displaying historical discourse for an audience. Caswell writes that archive sciences may be viewed as "a liminal field...not bound by a singular methodology or approach, providing fertile ground for new strategies to be forged unconstrained by previous conventions." ${ }^{3}$ Each culture sees the past, memory, and

\footnotetext{
${ }^{3}$ Caswell, Michelle. "On archival pluralism: what religious pluralism (and its critics) can teach us about archives." Archival Science 13, no. 4 (2013): 273-92. doi:10.1007/s10502-012-9197-y.
} 
'archives,' which can take many forms, in a different light. A plurality of "archival realities"4 encourages "energetic engagement with diversity," and "committed interaction with...difference" in order to welcome those who would be "excluded or marginalized" by a dominant archival practice (namely, Western archival traditions concerned with fixed, authoritative, written sources). ${ }^{5}$ That is, some traditions value oral histories over written records, and it is important to welcome those differences in order to create an archive that serves as a pluralistic reflection of history.

Difference in practical approaches reflects the "ever-increasing ways" in which people engage with and understand history, evidence, and memory. That is, the interpretations of an exhibit are endless, because the context is multifaceted. ${ }^{7}$ In light of the varied array of approaches to archives, Duff \& Harris, who identify themselves as influenced by opposing "streams" of thought about archives, "have found a mode of exploration at once hospitable to difference and committed to... an integrative instinct." ${ }^{\text {" Across }}$ "streams," it is understood that "records are always in the process of being made, that "their" stories are never ending," and that the scholars and archivists who engage with those records are also part of the context. Archivists and "users" of archives add to the never-ending, "ever-changing" story of records because we invite those records into the future and a new context. ${ }^{9}$

Duff \& Harris continue their discussion by centralizing archival description and deconstructing its relationship to narrativity. They write, "personal histories, institutional cultures, gender dynamics, class relations, and many other dimensions of meaning construction are always already at play in processes of records description."10 The archivist, guided by a certain system of values, makes decisions about what to "capture and make visible," "[remembering] certain aspects and [hiding] or [forgetting] others." 11 Archivists may claim objectivity in their descriptions, but "description is always storytelling-

\footnotetext{
4 ibid

${ }^{5}$ Caswell, Michelle. "On archival pluralism: what religious pluralism (and its critics) can teach us about archives." Archival Science 13, no. 4 (2013): 273-92. doi:10.1007/s10502-012-9197-y.

${ }^{6}$ Duff, Wendy M., and Verne Harris. "Stories and names: Archival description as narrating records and constructing meanings." Archival Science 2, no. 3-4 (2002): 263-85. doi:10.1007/bf02435625.

7 ibid

8 ibid

9 ibid

10 ibid

11 ibid
} 
intertwining facts with narratives, observation with interpretation," and the narrativity of archival description is "unavoidably subjective." ${ }^{12}$ Further, the subjectivity of the archivist bleeds over into the realm of power and the archivist's "capacities to privilege or to marginalize, to construct knowledge, to exercise control." ${ }^{13}$ Developing a narrative in the description of archives/records is itself an exercise of power which can be both "constructive and oppressive."14

Schwartz and Cook, similarly, discuss the significance of the archive as a means of controlling the past, where those in power--those who preserve historical materials--control the narrative of history. "Archives are social constructs," they write, and are by nature "about maintaining power, about the power of the present to control what is, and will be, known about the past, about the power of remembering over forgetting." 15 They also challenge the idea of archivists as "neutral, objective, impartial" players in archival description, asserting that even the "objective, neutral, positivist" view of "science" (i.e archive science) has been "demythologized," 16 where all science can be viewed as a social construct.

By way of exemplifying the position of the archivist as subjective narrator, Gilliland dedicates a section of an article to "situating" $" 17$ herself in the research she conducted in post-war Croatia. She writes that her own "experiential and epistemological lens" 18 often colors her reading of archives, and that she feels an obligation to inform the reader of her personal history. "It would be both epistemologically and ethically inappropriate for me not to acknowledge and to attempt to account for the personal context I bring to this research." She expands on her personal context by describing her upbringing in Northern Ireland at the height of the Troubles and her first-hand experience of military occupation and sectarianism.

I also drew from discourse analysis literature to inform this project. Paltridge writes that "social

\footnotetext{
12 ibid

${ }^{13}$ Duff, Wendy M., and Verne Harris. "Stories and names: Archival description as narrating records and constructing meanings." Archival Science 2, no. 3-4 (2002): 263-85. doi:10.1007/bf02435625.

14 ibid

${ }^{15}$ Schwartz, J. M., and Terry Cook. "Archives, records, and power: The making of modern memory." Archival Science, 2002. Accessed May 24, 2017. doi:10.1107/s0108768107031758/bs5044sup1.cif.

16 ibid

${ }^{17}$ Gilliland, Anne J. "Moving past: probing the agency and affect of recordkeeping in individual and community lives in postconflict Croatia." Archival Science 14, no. 3-4 (2014): 249-74. doi:10.1007/s10502-014-9231-3.

18 ibid
} 
and political issues are constructed and reflected in discourse." ${ }^{19}$ Neutrality is virtually impossible due to the social nature of language, and therefore a bias, perspective, or power dynamic is constantly at play in any type of discourse, from a newspaper article to a notice from a landlord. Critical analyses also take into account the fact that "ideologies are produced and reflected discourse," including "ways of representing

and constructing society such as relations of power, and relations based on gender, class, and ethnicity." 20 Lakoff writes extensively about the iterations of ideology perpetuated in political discourse both on an institutional level (within political parties or government and in the media) and in daily, person-to-person communication. He studies how liberals and conservatives construct their worldviews through discourse, particularly the metaphors each group uses to describe themselves and others. ${ }^{21}$ Americanism is a reflection of conservative discourses at work, and an understanding of the context informing those discourses is essential to developing an exhibit.

\section{The Method}

As an outsider, a non-archivist, this project began as scholarly interest in historical documents found in the Collection and unfolded from that point. The initial engagement with the material was the groundwork for my interest in the challenges one would face when curating a public exhibit of material they disagreed with. So, my method was simple: to go through the motions of curating and displaying an exhibit of material from Americanism and to take note of my experiences and reactions.

The first step was to single out certain documents in the Young Americans for Freedom folder that would be interesting to display. The first four documents in the exhibit were obvious choices, because they are visually striking and allowed me to write the beginning of my YAF narrative, the story the exhibit lays out. Once these documents were chosen, I wrote exhibit texts (see Appendix) to accompany them in the display cases. In order to write detailed, informative, and concisely-worded texts, I read each document as closely as possible in the time allowed.

\footnotetext{
${ }^{19}$ Paltridge, Brian. Discourse Analysis. 2nd ed. Bloomsbury Discourse. London: Bloomsbury, 2012.

${ }^{20}$ Paltridge, Brian. Discourse Analysis. 2nd ed. Bloomsbury Discourse. London: Bloomsbury, 2012.

21 "The war of the words." The Economist. July 13, 2013. Accessed May 24, 2017. http://www.economist.com/news/unitedstates/21581745-how-republicans-and-democrats-use-language-war-words.
} 
Selecting the rest of the documents I would eventually display was not as straightforward as I had hoped. I found myself lost in the 'world' of the archive, fixated on certain documents and completely overlooking others. Without the guidance of my advisor, who was able to maintain sight of our ultimate direction, the final exhibit would not look at all as it does today.

When all the documents were finally selected and I had written texts to accompany them in their display cases, my advisor and I invited the PSU Library Archives team to view this final 'draft' of the exhibit. We laid everything out in the order it would be displayed. The other archivists proceeded to read the exhibit. When they had finished, we sat down to discuss potential changes and improvements. Ultimately this process ended with the installation of the exhibit as a whole, which was carried out by me with support from the Archives team.

\section{The Discussion}

Duff \& Harris argue that "the primary medium of archival description is narrative,"22 and this project has been an experiment in the challenges, dangers, and benefits of narrative with regard to controversial archives. As users and keepers of archives, we wield power over the discourses we encounter. We bring our personal experiences of "institutional cultures, gender dynamics, class relations" 23 and our presuppositions about history into the archive, viewing the material through the lens of the present. In a new context, we reinvent history through our descriptions of it. "Every narrative construction of the past is by definition creative, a work of the imagination," 24 and driven by the convictions of the interpreter, in this case a student-archivist. Indeed, how we perceive the past is always malleable ${ }^{25}$; the power of narrative to bend the imagination asserts that malleability.

In developing a narrative about the Young Americans for Freedom, I was repeatedly confronted with the power I had over the documents I sought to represent. My values do not align with the values of

\footnotetext{
22 Duff, Wendy M., and Verne Harris. "Stories and names: Archival description as narrating records and constructing meanings." Archival Science 2, no. 3-4 (2002): 263-85. doi:10.1007/bf02435625.

23 ibid

24 ibid

25 Gilliland, Anne J. "Moving past: probing the agency and affect of recordkeeping in individual and community lives in postconflict Croatia." Archival Science 14, no. 3-4 (2014): 249-74. doi:10.1007/s10502-014-9231-3.
} 
the YAF, and I had many opportunities to scoff, gasp, and shake my head while studying the small folder filled with YAF discourses. Schwartz \& Cook assert that although archivists often see themselves as "neutral, objective,[and] impartial," in reality their creative power over records moves with them throughout the process of "appraisal and selection" and the "constantly evolving description, preservation, and use" of the material. ${ }^{26}$ Part of the process of representing this collection was to talk, to write, to flesh out ideas in an attempt to parse an underlying narrative without editorializing it with my own presuppositions. Writing the exhibit texts forced me to submit to the subjective power of language/discourse; I constantly questioned if I wrote what I wrote because it was true or because it was my opinion; ultimately such a distinction proved unhelpful. The literature supports my experience: "the representer's value system, shaped by and expressing [a particular worldview] is the final arbitrator on the content of a representation." 27 For better or for worse, my role as a 'neutral' player in the archives was doomed from the beginning of this project.

Duff \& Harris continue their analysis by arguing that "what we choose to stress and what we choose to ignore is unavoidably subjective, and the value judgments that archivists make affect in turn how researchers find, perceive, and use records." ${ }^{28}$ Such analysis could be taken farther to include audiences of public exhibits representing an archive; viewers of my exhibit are subject to my intellectual, creative, and narrative decisions about YAF. My engagement with Americanism and YAF took place in "the uncomfortable space of encounter with difference," 29 where I read opinions and analyses I found completely opposite to my own, but in that space I learned the careful balance of fairness, critical analysis, and blatant disagreement. I did not, nor do I at this juncture, wish to hide my biases, but rather

\footnotetext{
${ }^{26}$ Schwartz, J. M., and Terry Cook. "Archives, records, and power: The making of modern memory." Archival Science, 2002. Accessed May 24, 2017. doi:10.1107/s0108768107031758/bs5044sup1.cif.

${ }^{27}$ Duff, Wendy M., and Verne Harris. "Stories and names: Archival description as narrating records and constructing meanings." Archival Science 2, no. 3-4 (2002): 263-85. doi:10.1007/bf02435625.

28 ibid

${ }^{29}$ Caswell, Michelle. "On archival pluralism: what religious pluralism (and its critics) can teach us about archives." Archival Science 13, no. 4 (2013): 273-92. doi:10.1007/s10502-012-9197-y.
} 
"expose....and investigate how they shape and obscure the meanings of records." ${ }^{30}$ The value judgments we make about archives and historical narratives are real and must be deeply understood, not ignored.

To feign objectivity is to deny an archive, a narrative, a history of its humanity. That is, to impose an unnatural, scientific positivism ${ }^{31}$ on a record of human activity is to remove its most important context: human memory. What, that we know of, is certain about the past, which we did not experience? As Duff \& Harris wrote, context is essentially infinite because we constantly invite history into the present and study it in new ways. ${ }^{32}$ Language, that defining capability of humankind, is forever influenced by context and experience. ${ }^{33}$ When describing archives, creating narratives by which we represent collections, our only tool is language: the language of the fixed documents, and the language of our changing contexts surrounding the material. It follows that "archivists, then, should come to terms with the reality of storytelling in their descriptive work...by insisting that they are merely a conduit for a story which tells itself, leads to sterility and professional disingenuousness." ${ }^{34}$

\section{Conclusion}

My experience of exhibit-making for Americanism was personal, stimulating, and challenging. The challenge of exhibit-making, particularly in representing a political collection, one liable to stir controversy, is the archivist's confrontation with a lack of scientific objectivity. We must submit to our own biases and the biases of the material we study, describe, and represent. Engaging with those differences in worldview and perception, however, allow us to unpack and critique discourse in an open, honest manner. The goal is to display history for the impact it has on us today. We, the users and describers of archives, cannot sit idly by and watch old discourse — which may have promoted and apologized for such negative phenomena as white supremacy, violent imperialism, or the social impacts of capitalism - reassert itself in the discourse of today without question or critique. It is impossible to be

\footnotetext{
${ }^{30}$ Duff, Wendy M., and Verne Harris. "Stories and names: Archival description as narrating records and constructing meanings." Archival Science 2, no. 3-4 (2002): 263-85. doi:10.1007/bf02435625.

${ }^{31}$ Schwartz, J. M., and Terry Cook. "Archives, records, and power: The making of modern memory." Archival Science, 2002. Accessed May 24, 2017. doi:10.1107/s0108768107031758/bs5044sup1.cif.

${ }^{32}$ Duff, Wendy M., and Verne Harris. "Stories and names: Archival description as narrating records and constructing meanings." Archival Science 2, no. 3-4 (2002): 263-85. doi:10.1007/bf02435625.

${ }^{33}$ Paltridge, Brian. Discourse Analysis. 2nd ed. Bloomsbury Discourse. London: Bloomsbury, 2012.

34 ibid
} 
neutral on controversial topics whether we agree with them or not; all we can do is to invite the past into our current experiences and hope that it will teach us something. 


\section{Bibliography}

Caswell, Michelle. "On archival pluralism: what religious pluralism (and its critics) can teach us about archives." Archival Science 13, no. 4 (2013): 273-92. doi:10.1007/s10502-012-9197-y.

Duff, Wendy M., and Verne Harris. "Stories and names: Archival description as narrating records and constructing meanings." Archival Science 2, no. 3-4 (2002): 263-85. doi:10.1007/bf02435625.

Gilliland, Anne J. "Moving past: probing the agency and effects of recordkeeping in individual and community lives in post-conflict Croatia." Archival Science 14, no. 3-4 (2014): 249-74. doi:10.1007/s10502-014-9231-3.

Paltridge, Brian. Discourse Analysis. 2nd ed. Bloomsbury Discourse. London: Bloomsbury, 2012.

Schwartz, J. M., and Terry Cook. "Archives, records, and power: The making of modern memory." Archival Science, 2002. Accessed May 24, 2017. doi:10.1107/s0108768107031758/bs5044sup1.cif.

"The war of the words." The Economist. July 13, 2013. Accessed May 24, 2017. http://www.economist.com/news/united-states/21581745-how-republicans-and-democrats-uselanguage-war-words.

Young Americans for Freedom, Box 16, Charles White Americanism Collection, Portland State University Archives \& Special Collections, Portland. 
Appendix

\title{
"Conservatism in a revolutionary era":
}

Young Americans for Freedom and the college campus of the 1960s and 70s

\{\{ from the Charles White Americanism Collection\}\}

[Two framing text blocks]

\begin{abstract}
About the Americanism Collection
PSU Library Special Collections is home to the Charles M. White Americanism Collection which includes mailings, pamphlets, and other publications related to or disseminated by American far right conservative organizations from the 1950s through the early 1980s. Dr. White, a long-time faculty member of Portland State's Department of History, had focused his doctoral work on far left movements in the United States. As a counterbalance, he later shifted his scholarly focus to the other end of the political spectrum. For over three decades, Dr. White and his graduate students gathered, organized and preserved materials from dozens of organizations. The resulting collection records a historical spectrum of the political right in the United States, from policy-focused economic and social conservatism to more virulent perspectives that openly draw upon legacies of exclusion and discrimination.
\end{abstract}

\section{"Conservatism in a revolutionary era"}

In the wake of escalating American military involvement in Vietnam, a massive anti-war mobilizations emerged at colleges and universities across the world. From the Sorbonne in Paris to Kent State University in Ohio, campus life was erupting in protest. Here at Portland State in 1970, students and faculty blockaded the South Park Blocks, marching and demonstrating against the war in Vietnam, the military's physical transport of nerve gas across Oregon, the Kent State killings, and the imprisonment of Black Panther leader Bobby Seale. While the themes and images of those protests have become emblematic of that turbulent period, often overlooked is the cultivation of a new conservative movement on the same campuses at the same time. 


\section{Young Americans for Freedom}

The Young Americans for Freedom or YAF is a conservative youth organization formed in 1960 by William F. Buckley, Jr. and several of his contemporaries. The group was founded on the idea of promoting conservative values in young people during a time of heavy political mobilization by the left wing in the U.S and abroad. Today, YAF still operates on a number of college campuses under the umbrella of the For America Foundation.

\section{Conservatism for a New Generation (1960)}

The YAF published this conservative manifesto in 1960. It describes the need for a powerful conservative movement dedicated to preserving "the balance of civilization," and "tradition" in response to the rising tide of "deleterious revolutionary principles." The pamphlet calls for a new more "militant" conservatism to meet the combativeness of the left-wing. The tone is one of clashing ideologies, where revolutionary anti-capitalist and anti-war mobilization stands anathema to "traditional" American values. The "glory" of a new conservative movement would prevail in the "struggle against the Liberal collectivist Leviathan."

[Pull quote]

From YAF's Conservatism for the New Generation (1960)

Conservatism in a Revolutionary Era: . . . We are today historically in a situation created by thirty years of slow and insidious revolution at home and a half century of violent open revolution abroad. To conserve the true and the good under these circumstances is to restore an understanding (and a social structure reflecting that understanding) which has been all but buried; it is not to preserve the transient customs and prescriptions of the present. 


\section{The Fascist Threat to America (circa 1960s)}

"The thirst of modern liberalism's economic and political programs is toward an indigenous fascism . . Fear not the blackshirts, but rather that mild-mannered Government man in the brown tweed suit."

Seeking to demonstrate the flaws of liberalism, this YAF pamphlet draws parallels across the borders of land and history to compare American liberalism to German National Socialism (i.e. the Nazi Party) and Italian fascism (i.e. Mussolini's National Fascist Party). It argues that Weimar Germany and pre-war Italy were characterized by "collectivist" socialist institutions and regulations and draws comparisons to liberal movements in the United States.It describes the tools of of fascism--"whip-cracking mechanisms of repression"--with an emphasis on censorship of the press and "enforced publication of quantities of material reflecting the official view-point."

Pull quotes:

From YAF's The Fascist Threat to America

"The conservative, of course, distrusts government, with its vast monopoly of organized violence, its authority to promulgate law, and its economic power that exceeds that of any conceivable combination of private interests."

\section{From YAF's The Fascist Threat to America}

"Both the Kennedy and Johnson administrations have found it necessary to manipulate the news to a greater extent than has ever been witnessed before. This news management involves active intimidation of reporters by the President and his staff, cutting off news at the source, and virtual isolation of Pentagon and State Department personnel." 


\section{The Sharon Statement}

The Sharon Statement was written and adopted by the founders of the YAF in 1960, at the home of William F. Buckley, Jr in Sharon, Connecticut. It contains 12 statements of belief to be held by "young conservatives," establishing the ideological framework for future activism. These statements became the backbone of all regional, local, and campus YAF chapters. Each statement builds on the principles of the one before it, stressing the importance of state's rights, free market economics, and the struggle against communism, culminating with a question to guide American foreign policy: “...does it serve the just interests of the United States?"

\section{College \& Community Organizing Manual}

This manual is a step-by-step instruction guide for would-be conservative activists, complete with examples for chapter logos, newsletter monikers, and a template for drafting a chapter constitution. A newly formed YAF chapter has access to national conservative publications, including the YAF's own magazine, The New Guard, to distribute at local events. Chapter leaders are charged with "increasing the circulation of the YAF national publication, The New Guard...[by] soliciting subscriptions from businessmen in the community" to promote "the magazine, conservatism, and your local chapter." Guides like this one sought to inform and encourage local and campus-based conservative activism. The YAF National Advisory Board also published countless letters, issue papers, and manuals to support the efforts of conservatives in their own communities.

\section{"With your help"}

These documents are examples of fundraising appeals made by YAF in the 1960s. The National Advisory Board shared letters like these from Barry Goldwater, Ronald Reagan, and John Wayne to show support for YAF by well-known conservative voices. To encourage donations, these letters give descriptions and highlights of YAF successes in "promoting conservatism on our nation's campuses," including workshops for future chapter leaders and the distribution of conservative books and pamphlets "exposing communism." An outreach letter to an "Oregon Friend" highlights local chapter growth and the broadcast of the Oregon YAF's "Right On” on regional stations KGW and KINK. 


\section{“Tell It To Hanoi"}

YAF was deeply engaged in the campus conflict over the war in Vietnam, often serving as the conservative counter against the National Mobilization Committee Against the War in Vietnam (also known as 'The New Mobe,'). YAF played an integral role in staging a national campus referendum on the immediate withdrawal of U.S troops from Vietnam, supporting the conservative campus movement for a "no" vote.

YAF often met New Mobe demonstrations (like the "Spring Offensive" mentioned in these documents) with its own counter-protests. This letter to prospective donors states, "Members of the Young Americans for Freedom--50,000 strong--are countering the New Mobe wherever it raises its ugly head."

The message of the "Tell It To Hanoi" campaign was somewhat amorphous. It did advocate for a "no" vote on the referendum. But perhaps in recognition of growing public support for some level of troop withdrawal from Vietnam, “Tell It To Hanoi” also emphasized the importance of reiterating a strong anticommunist ideological position "to insure that...more than 40,000 other brave young Americans shall not have died in vain."

\section{The other campus battle}

In addition to the Vietnam debate, YAF characterized campuses as battlegrounds for the fight to temper "radical political philosophy" in classes and in public spaces. This letter and its attachment of "some excerpts from a poll of college professors" demonstrate one of the major concerns held by YAF leadership: that college professors were increasingly "radical" and unfairly imparting their political philosophy on students without providing students with access to conservative political viewpoints.

These mailers highlight for recipients the physical, sometimes violent disruption of campus life by antiwar demonstrations and "revolutionaries," naming such actions collectively as the "Campus Crisis" and "New Left Violence." One mailer on this topic includes pieces from Parade Magazine and the L.A. Herald Examiner but each features somewhat different characterizations of YAF responses. The Herald Examiner declares YAF members as the "unsung heroes" in the conflict between campus liberals and 
conservatives, for "waging an important battle in a quiet way" while "Students . . Get Ready for Battle," notes "YAF will no longer wait out each SDS move before it acts. It will use the same harassment techniques, though just short of breaking the law, that SDS used against the college administrations."

YAF also spoke out against other forms of "student subversion," such as the alleged connection between liberal student organizations (like Students for a Democratic Society) with the "international MarxistLeninist apparatus." Questions on this Campus Crisis Poll surface a major complaint made by YAF, that campus administrators "failed to protect the integrity of the campus forum" by allowing liberal groups to “disrupt campus activities" from classes to extra-curricular lectures and events. 